\title{
EVALUASI ADOPSI TEKNOLOGI BUDIDAYA DAN KELAYAKAN USAHATANI PADI DI PROVINSI SULAWESI SELATAN
}

\author{
Amar K. Zakaria \\ Pusat Sosial Ekonomi dan Kebijakan Pertanian \\ Jl. A. Yani No. 70 Bogor, Jawa Barat \\ Contact person: 0856-7868-877
}

\begin{abstract}
Rice is the strategic commodity as the main foodstuff and the source of the income of most rural households. The application of cultivation technology played an important role towards the increase in the production and the productivity of lowland rice. Therefore, the application of the innovation of recommendation technology in the level of the farmer was the strategy in the increase program in the production of the national rice towards the continuous self-sufficiency. This research was carried out during 2012 in the Sidrap Regency and Luwu, Provinsi South Sulawesi with the survey method. The primary data was gathered through the interview to the respondent's 80 farmers with the questionnaire structure filling. The data was processed with cross tabulation and the level of the appropriateness of the farming was measured with Gross B/C the ratio and profitability. Results of the research showed that adoption of rice technology in the farmer level was adopted with technology recommendation. The analysis of benefit and cost to get gross $B / C>1$, based on that the farming of lowland rice in the research territory gave the profit and economically appropriate was made an effort operation.
\end{abstract}

Key words : the rice farming, technology, the self-sufficiency, participation

\begin{abstract}
Abstrak: Beras merupakan komoditas strategis karena sebagai bahan makanan pokok dan sumber pendapatan sebagian besar rumah tangga perdesaan. Penerapan teknologi budidaya berperan penting terhadap peningkatan produksi dan produktivitas padi sawah. Oleh karena itu, penerapan inovasi teknologi rekomendasi di tingkat petani merupakan strategi dalam program peningkatan produksi beras nasional menuju swasembada berkelanjutan. Penelitian ini dilaksanakan pada tahun 2012 di Kabupaten Sidrap dan Luwu, Provinsi Sulawesi Selatan dengan metoda survei. Data primer dikumpulkan melalui wawancara kepada 80 petani responden dengan pengisian kuesioner terstruktur. Data diolah dengan tabulasi silang dan tingkat kelayakan usahatani diukur dengan Gross $\mathrm{B} / \mathrm{C}$ ratio dan profitabilitas. Hasil penelitian menunjukkan bahwa adopsi teknologi padi di tingkat petani belum sudah sesuai anjuran. Hasil analisis biaya dan pendapatan diperoleh nilai $\mathrm{B} / \mathrm{C}$ lebih dari satu, berarti usahatani padi sawah di wilayah penelitian memberi keuntungan dan secara ekonomi layak diusahakan.
\end{abstract}

Kata kunci: usahatani padi, teknologi, swasembada, partisipasi

\section{PENDAHULUAN}

Beras merupakan komoditas strategis yang berperanan penting dalam perekonomian dan ketahanan pangan nasional, karena sampai saat ini beras menjadi bahan makanan pokok rakyat
Indonesia dan menopang kehidupan lebih dari 60 persen rumah tangga petani.

Keberhasilan peningkatan produksi padi nasional pada akhir-akhir ini, menurut Badan Litbang Pertanian (2005) lebih banyak disumbang dari peningkatan produktivitas yang berkontribusi sebesar 56,2 persen dan 
sumbangan dari luas areal panen sebesar 26,3 persen. Oleh karena itu, penerapan inovasi teknologi budidaya padi di tingkat petani sesuai anjuran merupakan salah satu strategi dalam program peningkatan produksi beras nasional menuju swasembada berkelanjutan (Deptan, 2008). Terkait hal ini, Simatupang (2004) mengemukakan bahwa langkah terobosan untuk mempercepat dan memantapkan inovasi teknologi merupakan paradigma baru dalam proses adopsi inovasi teknologi. Dan untuk itu, menurut Syahyuti (2007) partisipasi petani diperlukan dalam mengadopsi teknologi untuk keberlanjutan pembangunan.

Menurut Sumarno (2010) bahwa dengan penerapan teknologi revolusi hijau dalam budidaya tanaman pangan di Indonesia dalam kurun waktu empat puluh tahun (19702010) telah berhasil meningkatkan produksi padi tiga kali hingga empat kali lipat. Dalam kurun waktu 5 tahun terakhir (2008-2012) produksi padi nasional meningkat rata-rata 3,44 persen per tahun, yaitu dari 60,82 juta ton (2008) menjadi 68,96 juta ton GKG (Gabah Kering Giling) pada tahun 2012.

Kontribusi ketersediaan sumberdaya lahan sawah irigasi sangat berperan penting dan menjadi andalan utama dalam pengadaan produksi padi nasional, yaitu sebesar 90 persen dari total luas lahan baku usahatani padi di Indonesia (Fagi, 2004). Berdasar keberadaan luas lahan sawah irigasi dari sekitar 5,24 juta hektar, sebesar 1,24 juta hektar diusahakan satu kali padi atau memiliki Intensitas Pertanaman (IP) sebesar 100 dan sebesar 4,0 juta hektar diusahakan dua kali tanam padi atau lebih dengan IP 200 dan IP 300 yang diusahakan di wilayah sentra padi (Swastika et al., 2006).

Kegiatan budidaya padi kini dihadapkan pada kendala stagnasi peningkatan produksi padi nasional, terutama disebabkan oleh kurang berhasilnya peningkatan produktivitas. Kondisi tersebut berkaitan erat dengan pencapaian batas atas potensi varietas unggul yang ada di tingkat petani, sebagaimana ditunjukkan kesenjangan hasil antara hasil penelitian dengan hasil petani (Las et al., 2004). Sejalan dengan itu, Fagi et al. (2002) diperlukan varietas unggul baru yang daya hasilnya lebih tinggi seperti Cibogo, Cigeulis, IR-64 dan Mekongga.

Penggunaan benih unggul bermutu menjadi salah satu faktor kunci dalam upaya meningkatkan produktivitas padi, namun Nurmanaf et al. (2005) melaporkan bahwa petani padi sawah di sentra produksi masih banyak yang menggunakan benih produksi sendiri untuk tanam padi kedua kalinya. Kondisi ini sejalan dengan Sayaka et al. (2006) bahwa dalam periode tahun 1996-2005 petani pengguna benih berlabel masih rendah yaitu sekitar 22 persen.

Pelaksanaan kegiatan program pengembangan budidaya padi berdasarkan konsep Pengelolaan Tanaman Terpadu (PTT) merupakan model yang mengintegrasikan komponen teknologi sinergis yang efisien, spesifik lokasi dan melibatkan partisipasi aktif petani dengan mengdepankan aspek kelestarian lingkungan.

Sejalan dengan hal tersebut, Djoeroemana et al. (2007) mengemukakan bahwa pengembangan wilayah perdesaan berbasis usahatani hanya mungkin dilakukan apabila ada faktor pengikat yang menumbuhkan partisipasi aktif masyarakat dengan pengembangan sumberdaya manusia perdesaan secara terarah. Dan Syahyuti (2008) menekankan bahwa modal sosial berperan untuk mengikat semua yang terlibat kerjasama.

\section{METODE PENELITIAN}

Penelitian dilaksanakan pada tahun 2012 di Kabupaten Sidrap dan Kabupaten Luwu, Provinsi Sulawesi Selatan dengan menggunakan metoda survei. Lokasi penelitian merupakan wilayah berbasis ekosistem lahan sawah irigsi, yaitu Desa Carawali, Kecamatan Watang Hulu, Kabupaten Sidrap dan Desa Salujambu, Kecamatan Lamasi, Kabupaten Luwu. Data primer dikumpulkan melalui teknik wawancara melalui pengisian kuesioner terstruktur kepada 80 petani contoh yaitu 40 petani di Desa Carawali dan 40 petani di Desa Salujambu.

Data yang dikumpulkan meliputi karakteristik rumah tangga petani, keragaan penerapan teknologi budidaya padi, tingkat penggunaan sarana produksi dan tenaga kerja serta tingkat produktivitas usahatani padi.

Data diolah dengan tabulasi silang yang disajikan dalam bentuk tabel. Untuk mengukur tingkat partisipasi penerapan teknologi budidaya padi dilakukan komparasi dengan teknologi anjuran. Sedangkan untuk 
mengetahui tingkat kelayakan usahatani padi, secara sederhana dinilai dengan analisis gross $\mathrm{B} / \mathrm{C}$ ratio, yaitu nilai imbangan pendapatan kotor dan biaya total usahatani. Apabila nilai $\mathrm{B} / \mathrm{C}>1$ berarti usahatani padi layak diusahakan. Selain itu dilakukan pendekatan dengan menghitung tingkat profitabilitas usahatani dengan formula sebagai berikut:

1. $\mathrm{TL}=\mathrm{TR}-\mathrm{TC}$

dimana :

$\mathrm{TL}=$ Keuntungan (profit)

$\mathrm{TR}=$ Total penerimaan usahatani (revenue)

$\mathrm{TC}=$ Total biaya usahatani $($ cost $)$

2. Profitabilitas $(\operatorname{Pr})=(\pi / \mathrm{TR}) \times 100 \%$

3. Gross $\mathrm{B} / \mathrm{C}=\mathrm{TR} / \mathrm{TC}$

\section{HASIL DAN PEMBAHASAN}

\section{Karakteristik Petani Contoh}

Kondisi karakteristik rumah tangga petani, seperti umur dan pendidikan formal, pengalaman bertani, jumlah anggota rumah tanga (ART) dan ART yang terlibat aktif dalam usahatani, pengalaman bertani, luas lahan garapan, status petani dan sumber modal usahatani menjadi faktor intern yang berpengaruh terhadap sikap dan motivasi petani dalam menjalankan kegiatan usahataninya.

Dilihat dari usia, petani di wilayah desa Carawali (Sidrap) rata-rata berumur 44,6 tahun dengan kisaran dari 29-56 tahun. Sedangkan di desa Salujambu (Luwu) rata-ratanya 48,2 tahun dengan kisaran 28-58 tahun. Dengan kondisi rata-rata umur petani di kedua desa tersebut, berada pada posisi golongan usia produktif yang berarti secara fisik sangat mendukung untuk melakukan berbagai aktivitas usahatani. Dari segi tingkat pendidikan formal yang diselesaikan di kedua desa penelitian, rataratanya sudah tamat sekolah dasar sehingga dengan memiliki pengalaman bertani lebih dari 18 tahun, maka dalam menetapkan keputusan untuk menerima dan menerapkan teknologi budidaya padi yang dianjurkan cukup memadai dengan pengetahuan yang dimilikinya. Secara sederhana menurut Ajid (1985) kondisi tersebut merupakan manifestasi dari perilaku seseorang dalam mewujudkan perannya untuk mencapai tujuan tertentu.

Berdasar jumlah anggota rumah tangga di kedua desa penelitian rata-ratanya sebesar 4 (empat) jiwa, namun yang terlibat dalam kegiatan usahatani hanya sekitar 1,4-1,5 jiwa. Dengan kondisi tersebut, potensi sumberdya tenaga kerja keluarga cukup tersedia karena pada dasarnya petani lebih mengutamakan curahan tenaga kerja keluarga dalam menjalankan usahataninya. Dilihat dari ratarata luas lahan garapan di Carawali sebesar 0,72 hektar dengan kisaran 0,45 - 1,70 hektar dan di Salujambu sebesar 0,85 hektar dengan kisaran 0,50-2,50 hektar. Pada umumya status penguasaan lahan garapan adalah pemilik penggarap $(74 \%-78 \%)$ dengan sumber modal sebesar $72 \%$ swadana petani di Carawali dan $60 \%$ swadana petani di Salujambu (Tabel 1).

Tabel 1. Karakteristik Petani Contoh di Wilayah Penelitian Provinsi Sulawesi Selatan, 2012

\begin{tabular}{|c|c|c|c|c|}
\hline \multirow[t]{2}{*}{ Uraian } & \multicolumn{2}{|c|}{$\begin{array}{l}\text { Desa Carawali } \\
\text { Kab. Sidrap }\end{array}$} & \multicolumn{2}{|c|}{$\begin{array}{c}\text { Desa Salujambu } \\
\text { Kab. Luwu }\end{array}$} \\
\hline & Rataan & Kisaran & Rataan & Kisaran \\
\hline 1. Umur petani (th) & 44,6 & $29-56$ & 48,2 & $28-58$ \\
\hline 2. Pendidikan formal (th) & 6,7 & $3-14$ & 6,4 & $3-12$ \\
\hline 3. Pengalaman bertani (th) & 18,4 & $9-28$ & 21,2 & $10-32$ \\
\hline 4. Jumlah ART (jiwa) & 3,9 & $2-6$ & 4,1 & $2-6$ \\
\hline 5. ART terlibat tani (jiwa) & 1,4 & $1-3$ & 1,5 & $1-3$ \\
\hline 6. Luas garapan (ha) & 0,72 & $0,45-1,70$ & 0,85 & $0,50-2,50$ \\
\hline \multicolumn{5}{|l|}{ 7. Status petani $(\%)$} \\
\hline - Pemilik penggarap & 78,0 & - & 74,0 & - \\
\hline - Penggarap & 22,0 & - & 26,0 & - \\
\hline \multicolumn{5}{|l|}{ 8. Sumber modal (\%) } \\
\hline - Swadana petani & 72,0 & - & 60,0 & - \\
\hline - Kredit bayar panen & 28,0 & - & 40,0 & - \\
\hline
\end{tabular}

Sumber : Data Primer, 2012. 
Keragaan Penerapan Teknologi Budidaya Padi

Dalam pelaksanaan pembangunan pertanian yang berkelanjutan pada dasarnya harus memiliki 3 (tiga) tujuan, yaitu: tujuan ekonomi (efisiensi dan pertumbuhan), tujuan sosial (kepemilikan lahan usahatani yang berkeadilan), dan tujuan ekologis (kelestarian sumberdaya alam dan lingkungan), yang ketiganya saling terkait. Untuk mencapai kondisi tersebut, menurut Hamdani (2006) diperlukan proses menstimulasi dan memotivasi masyarakat tani dengan memberdayakan kemandirian melalui peningkatan kualitas sumberdaya manusianya. Tindakan yang demikian akan membentuk sikap dan kepercayaan diri dalam mengambil keputusan (Farida, 2006). Sejalan dengan upaya penerapan inovasi teknologi yang dilaksanakan secara teratur dalam kesatuan tindakan menjadi faktor kunci dan bagian yang tidak terpisahkan untuk mencapai tujuan bersama (Sumardi, 2006). Oleh karena itu, partisipasi diperlukan untuk menjamin keberhasilan penerapan teknologi budidaya dalam peningkatan produksi dan produktivitas usahatani sehingga pendapatan petani meningkat pula (Kasryno et al., 2001; Syahyuti, 2006). Secara umum inovasi teknologi anjuran merupakan bentuk paket yang mencakup keseluruhan komponen teknologi yang ada meliputi teknologi mekanis, kimiawi, dan biologis dan menjadi informasi terhadap teknologi yang bersangkutan (Gunawan, 1988).

Keragaan penerapan teknologi budidaya padi di tingkat petani dari hasil penelitian adalah sebagai berikut.

\section{Teknologi Pengolahan Tanah}

Kegiatan pengolahan tanah untuk usahatani padi sawah di lokasi penelitian setiap tanam dilakukan pengolahan traktor tangan, yaitu dibajak dan digaru. Dengan perlakuan tersebut, berarti kegiatan pengolahan tanah telah sesuai dengan yang dianjurkan. Untuk musim tanam penghujan periode waktu pengolahan tanah adalah selama 4 (empat) minggu, sedangkan untuk musim tanam kemarau 2-3 minggu lahan siap ditanami.

Tabel 2. Penerapan Teknologi Benih di Desa Penelitian Provinsi Sulawesi Selatan, 2012

\begin{tabular}{lrrrr}
\hline \multicolumn{1}{c}{ Uraian } & \multicolumn{2}{c}{ Musim hujan } & \multicolumn{2}{c}{ Musim kemarau } \\
\cline { 2 - 5 } & Carawali & Salujambu & Carawali & Salujambu \\
\hline 1. Varietas ditanam (\%) & 50 & 45 & & \\
- Ciherang & 10 & 0 & - & 10 \\
- Ciliwung & 0 & 15 & 35 & - \\
- Mekongga & 40 & 40 & 45 & 50 \\
- IR-64 & & & & \\
2. Kualitas benih (\%) & 75 & 80 & 60 & 65 \\
- Berlabel & 35 & 40 & 40 & 35 \\
- Tidak berlabel & & & & \\
3. Sumber benih & 60 & 70 & 60 & 55 \\
- Beli di kios & 15 & 10 & - & 10 \\
- Bantuan/program & 25 & 20 & 40 & 35 \\
- Benih sendiri & & & & \\
4. Sistem tanam (\%) & 75 & 65 & 80 & 80 \\
- Tabela & 25 & 35 & 20 & 20 \\
- Tanam pindah & & & & \\
& 48,2 & 46,8 & 46,6 & 46,2 \\
5. Jumlah benih & 32,4 & 31,6 & 31,2 & 30,8 \\
- Tabela (kg/ha) & & & & \\
- Tanam pindah (kg/ha & & & & \\
\hline
\end{tabular}

Sumber : Data Primer, 2012. 


\section{Teknologi Benih}

Menurut Sumarno (2011) bergantinya varietas padi yang lebih unggul yang ditanam petani dari waktu ke waktu, menunjukkan bukti empiris bahwa varietas unggul terbaru lebih baik dari varietas sebelumnya. Dimana untuk periode tahun 2001-2010 petani memilih varietas Ciherang, Cigeulis, Cibogo, IR-64, Sinta Nur, Mekongga dan Inpari.

Dilihat dari varietas yang ditanam oleh petani contoh di kedua desa penelitian, semuanya memakai varietas unggul terbaru. Untuk musim hujan (MH) yang dominan ditanam adalah Ciherang yaitu 50 persen di Desa Carawali dan 45 persen di Desa Salujambu dan IR-64 sebesar 40 persen di kedua desa penelitian. Sedangkan pada musim kemarau (MK) terjadi perubahan pemakaian varietas yang ditanam dan yang dominan ditanam adalah Mekongga (35-40\%) dan IR-64 (45-50\%). Dengan kondisi tersebut tampak bahwa IR-64 merupakan varietas yang paling disukai petani, karena selain produktivitasnya cukup tinggi juga tampilan gabahnya lebih besar dengan rasa nasi yang lebih enak.

Berdasar kualitas benih, untuk MH di Desa Carawali petani pengguna memakai benih berlabel adalah sebesar 75 persen dan petani di Desa Salujambu 80 persen. Dilihat dalam pengadaannya benih umumnya bersumber dari membeli dari kios dan bantuan program. Sedangkan pemakaian benih untuk kegiatan tanam MK, petani yang menggunakan benih hasil produksi sendiri (tidak berlabel) terjadi peningkatan yaitu dari 20-25 persen menjadi 35-40 persen. Kondisi tersebut dikarenakan adanya petani yang melakukan pergantian benih setiap dua kali tanam padi.

Sistem tanam yang saat ini banyak dilakukan petani, baik untuk kegiatan $\mathrm{MH}$ maupun MK adalah Tabela (Tanam Benih Langsung) yaitu 70-75 persen di Carawali dan 65-70 persen di Salujambu dengan tingkat pemakaian benih sebanyak 46-48 kg/hektar. Sedangkan petani yang melakukan tanam pindah sekitar 25-30 persen pada $\mathrm{MH}$ dengan pemakaian benih sebanyak $31-32 \mathrm{~kg} /$ hektar dan pada MK petani yang melakukannya sekitar 30-35 persen dengan pemakaian benih sebanyak $31 \mathrm{~kg} /$ hektar. Dengan tingkat pemakaian benih tersebut, berarti sudah mengacu pada anjuran. Secara rinci penerapan teknologi benih di kedua desa contoh disajikan pada Tabel 2.

\section{Teknologi Pemupukan}

Pemupukan tanaman secara tepat waktu dan tepat jumlah secara berimbang menjadi faktor penentu dalam peningkatan produktivitas.

Hasil penelitian menunjukkan bahwa dalam hal jenis pupuk yang digunakan di kedua desa penelitian, umumnya hanya menggunakan dua jenis pupuk yaitu urea dengan petani pengguna 100 persen dan SP-36 penggunanya 80-90 persen pada musim hujan dan 80-85 persen pada musim kemarau. Sedangkan petani yang melakukan pemupukan secara lengkap berdasar jenis pupuknya, hanya sebesar 25-30 persen petani pemakainya di Desa Carawali dan 18-20 persen di Desa Salujambu.

Dilihat dari jumlah takaran/dosis menurut jenis pupuk yang digunakan, untuk pemakaian pupuk nitrogen (urea dan ZA) baik untuk MH maupun MK di kedua desa contoh, jumlah takarannya sudah cukup memadai sebagaimana yang dianjurkan, yaitu sekitar 286-308 kg/ha untuk MH dan 264-295 kg/ha untuk MK. Demikian pula untuk jenis pupuk phosfor (SP-36) untuk MH takarannya 86-92 $\mathrm{kg} / \mathrm{ha}$ dan MK sebanyak 84-86 kg/ha.Untuk pemakaian pupuk $\mathrm{KCl}$, hanya dijumpai di Desa Carawali yang dilakukan pada kegiatan $\mathrm{MH}$ saja dan penggunanya hanya sebesar 15 persen dengan takaran yang masih rendah yaitu 17 $\mathrm{kg} / \mathrm{ha}$. Sedangkan untuk pemakaian pupuk NPK/phonska petani penggunanya baru sekitar 20-30 persen dengan takaran $38-46 \mathrm{~kg} / \mathrm{ha}$ untuk MH dan sekitar 18-25 persen petani penggunanya untuk MK dengan takaran 32-38 $\mathrm{kg} /$ ha. Kondisi ini menunjukkan bahwa pelaksanaan pemupukan secara lengkap dan berimbang belum sepenuhnya diterapkan petani. Menurut petani, disamping ketersediaan pupuk $\mathrm{KCl}$ dan NPK di wilayah usahataninya masih terbatas, juga harga beli dari kedua jenis pupuk tersebut relatif mahal.

Pemberian pupuk pada pertanaman padi di kedua desa contoh, pada umumnya diberikan dua kali aplikasi dengan cara ditaburkan/disebar. Untuk kasus petani yang memberikan tiga kali aplikasi, hanya terjadi pada MH di Desa Carawali. Setiap aplikasi pemupukan, semua jenis pupuk disatukan/dioplos dengan takaran sebagin pada 
aplikasi pertama yaitu pada umur tanaman 1021 hari dan aplikasi kedua pada pertanaman berumur 35-45 hari setelah tanam. Teknologi pemupukan pada padi sawah, sebagian besar dari petani menyatakan mendapat informasi dari penyuluh $(65-75 \%)$ dan sekitar $20-35 \%$ berdasar dari hasil pengalaman petani sendiri (Tabel 3).

Tabel 3. Keragaan Tingkat Partisipasi Teknologi Pemupukan pada Usahatani Padi Sawah di Desa Penelitian Provinsi Sulawesi Selatan, 2012

\begin{tabular}{|c|c|c|c|c|}
\hline \multirow[b]{2}{*}{ Uraian } & \multicolumn{2}{|c|}{ Desa Carawali } & \multicolumn{2}{|c|}{ Desa Salujambu } \\
\hline & $\begin{array}{c}\mathrm{MH} \\
(\mathrm{n}=40)\end{array}$ & $\begin{array}{c}\text { MK } \\
(n=40)\end{array}$ & $\begin{array}{c}\mathrm{MH} \\
(\mathrm{n}=40)\end{array}$ & $\begin{array}{c}\mathrm{MK} \\
(\mathrm{n}=40)\end{array}$ \\
\hline \multicolumn{5}{|l|}{ 1. Jenis pupuk (kg/ha) } \\
\hline - Urea & $242(100)$ & $254(100)$ & $258(100)$ & $236(100)$ \\
\hline$-\mathrm{ZA}$ & $64(35)$ & $41(25)$ & $28(15)$ & $28(15)$ \\
\hline - SP-36 & $86(80)$ & $86(80)$ & $92(90)$ & $84(85)$ \\
\hline$-\mathrm{KCl}$ & $17(15)$ & - & - & - \\
\hline - NPK & $46(30)$ & $38(25)$ & $38(20)$ & $32(18)$ \\
\hline Dosis (kg/ha) & $455(100)$ & $419(100)$ & $416(100)$ & $380(100)$ \\
\hline Partisipasi (\%) & & & & \\
\hline \multicolumn{5}{|c|}{ 2. Frekuensi pemupukan (\%) } \\
\hline - Satu kali & - & - & - & - \\
\hline - Dua kali & 92,5 & 100 & 100 & 100 \\
\hline - Tiga kali & 7,5 & - & - & - \\
\hline \multicolumn{5}{|l|}{ 3. Cara pemupukan $(\%)$} \\
\hline - Dibenamkan & - & - & - & - \\
\hline - Ditaburkan & 100 & 100 & 100 & 100 \\
\hline \multicolumn{5}{|l|}{ 4. Sumber Teknologi } \\
\hline - Penyuluh & 77,5 & 77,5 & 65,0 & 65,0 \\
\hline - Kios saprodi & 2,5 & 2,5 & - & - \\
\hline - Petani & 20,0 & 20,0 & 35,0 & 35,0 \\
\hline
\end{tabular}

Sumber : Data Primer, 2012.

Keterangan : ( ) adalah angka persentase petani pemakai.

\section{4, Teknologi Pemeliharaan}

Kegiatan pemeliharaan pertanaman secara baik dan teratur merupakan kegiatan yang penting dan berpengaruh dalam mempertahankan produktivitas yang telah dicapai. Pengendalian organisme pengganggu tanaman (OPT) pada usahatani padi sawah saat ini yang dianjurkan adalah perlakuan yang lebih bijaksana dengan penerapan PHT (pengendalian hama terpadu), sehingga kelestarian lingkungan tetap terjaga dengan baik. Namun dalam penerapannya di tingkat petani belum berjalan sebagaimana mestinya.

Berdasar pada aktivitas pengendalian OPT yang dilakukan oleh petani di desa contoh, pada umumnya belum diterapkan dalam budidaya padi sawah walaupun ada kelompok tani yang sudah mengikuti pelatihan SLPTT (Sekolah Lapang Pengendalian Hama Terpadu). Kegiatan penyemprotan dilakukan apabila terlihat adanya gejala serangan pada pertanaman, oleh karena itu sebagian besar petani $(70-85 \%)$ melalukan penyemprotan sebanyak 2-3 kali aplikasi. Bahan pestisida yang umum digunakan adalah pestisida cair dengan takaran $1,74-1,88$ 1/ha di Desa Carawali dan 2,14 - 2,42 1/ha di Desa Salujambu. Untuk pemakaian pestisida berupa butiran (granular) hanya dijumpai di Desa Carawali dan petani penggunanya hanya sekitar 15-25 persen.

Kegiatan penyiangan di kedua desa contoh dilakukan sebanyak dua kali yaitu pada umur tanaman 14-17 hari penyiangan pertama dan kedua pada tanaman berumur 35-40 hari setelah tanam. Dalam penyiangan ini, sekitar 60-65 persen petani penggunanya di Desa Carawali dan 55 persen petani di Desa Salujambu. Untuk sistem pemberian air, semua petani melakukan kegiatan pengeringan areal lahan pertanaman padi secara berkala (Tabel 4) 
Amar K. Zakaria: Evaluasi Adopsi Teknologi Budidaya Dan Kelayakan Usahatani ...

Tabel 4. Keragaan Kegiatan Pemeliharaan Tanaman pada Usahatani Padi Sawah di Desa Penelitian Provinsi Sulawesi Selatan, 2012

\begin{tabular}{|c|c|c|c|c|}
\hline \multirow{2}{*}{ Uraian } & \multicolumn{2}{|c|}{ Desa Carawali } & \multicolumn{2}{|c|}{ Desa Salujambu } \\
\hline & $\mathrm{MH}$ & MK & $\mathrm{MH}$ & MK \\
\hline \multicolumn{5}{|l|}{ 1. Penyemprotan (\%) } \\
\hline - Disemprot berkala & - & - & - & - \\
\hline $\begin{array}{l}\text { - Disemprot sewaktu ada } \\
\text { serangan }\end{array}$ & 100 & 100 & 100 & 100 \\
\hline - Tidak disemprot & - & - & - & - \\
\hline \multicolumn{5}{|l|}{ 2. Pemakaian pestisida } \\
\hline - Cairan (1/ha) & $1,88(100)$ & $1,74(100)$ & $2,14(100)$ & $2,42(100)$ \\
\hline - Tepung (kg/ha) & $0,34(30)$ & $0,30(25)$ & $0,38(20)$ & $0,38(20)$ \\
\hline - Butiran (kg/ha) & $2,10(25)$ & $1,48(15)$ & - & - \\
\hline \multicolumn{5}{|l|}{ 3. Frekuensi penyemprotan } \\
\hline$-2-3$ kali & 77,5 & 85,0 & 70,0 & 70,0 \\
\hline$->3$ kali & 22,5 & 15,0 & 30,0 & 30,0 \\
\hline \multicolumn{5}{|l|}{ 4. Frekuensi penyiangan } \\
\hline - satu kali & - & - & - & - \\
\hline - dua kali & 100 & 100 & 100 & 100 \\
\hline - tiga kali & - & - & - & - \\
\hline 5. Pengguna herbisida (\%) & 65,0 & 60,0 & 55,0 & 55,0 \\
\hline \multicolumn{5}{|l|}{ 6. Pengairan } \\
\hline - Digenangi terus & - & - & - & - \\
\hline - Dikeringkatkan berkala & 100 & 100 & 100 & 100 \\
\hline
\end{tabular}

Sumber : Data Primer, 2012

\section{Analisis Kelayakan Usahatani Padi}

Keberhasilan aktivitas usahatani ditentukan oleh besaran biaya yang dikorbankan dengan tingkat pendapatan usahatani. Budidaya padi sawah di kedua desa penelitian umumnya dua kali tanam, yaitu padi musim hujan $(\mathrm{MH})$ yang ditanam pada bulan Nopember dan padi musim kemarau (MK) yang ditanam pada bulan Maret.

Dalam analisis ini biaya usahatani yang dinilai meliputi: biaya sarana produksi (benih, pupuk dan obat-obatan), biaya tenaga kerja pengolahan tanah, pemeliharaan pertanaman dan kegiatan panen. Pemakaian tenaga kerja keluarga dipilah untuk melihat seberapa besar kontribusinya. Biaya usahatani padi per hektar per musim adalah $\mathrm{Rp} 8,21$ - Rp 8,51 juta. Dilihat dari struktur pengeluaran, alokasi terbesar adalah untuk tenaga kerja yaitu 7880persen, dimana kontribusi tenaga keluarga sekitar 13-16 persen. Selanjutnya, alokasi biaya untuk pengadaan sarana produksi adalah 18-20 persen dan yang terbesar untuk pengadaan pupuk $(8,70 \%$ - 10,16\%). Kondisi ini menunjukkan bahwa pemakaian pupuk dalam usahatani padi sawah merupakan keharusan. Besaran alokasi biaya dan proporsinya dari masing-masing komponen dalam usahatani padi sawah di kedua desa contoh di Sulawesi Selatan menurut musim tanam disajikan pada Tabel 5.

Berdasarkan tingkat produktivitas padi yang dicapai responden di Desa Carawali dan Salujambu (Lampiran 1 dan 2), maka rata-rata produktivitas yang diperoleh, untuk $\mathrm{MH}$ adalah sebesar $6.200 \mathrm{~kg}$ di Desa Carawali dan 5.900 kg GKP (Gabah Kering Pungut) di Desa Salujambu. Sedangkan untuk padi MK adalah $5.700 \mathrm{~kg}$ di Carawali dan $5.600 \mathrm{~kg}$ di Salujambu. Tingkat pendapatan kotor usahatani padi di MH adalah Rp 15,34 - Rp 16,12 juta dan padi MK sebesar Rp 14,60 - Rp 14,82 juta. Dengan kondisi tersebut, maka keuntungan bersih dari usahatani padi $\mathrm{MH}$ diperoleh $\mathrm{Rp}$ 7,06 - Rp 7,61 juta dan padi MK sebesar Rp 6,30 - Rp 6,60 juta.

Hasil analisis pendapatan dan biaya usahatani (Gross B/C) padi sawah di lokasi penelitian (Desa Carawali dan Salujambu) pada kegiatan musim hujan dan kemarau 2012, diperoleh dengan nilai lebih dari satu, berarti usahatani padi sawah di kedua desa contoh adalah layak diusahakan dan cukup efisien karena nilai profitabilitasnya yang kompetitif yang cenderung setara dengan biaya usahatani. 
Hal ini tidak terlepas dari membaiknya tingkat penerapan teknologi budidaya padi oleh petani, sehingga produktivitas yang dicapai meningkat.
Selain itu, harga jual padi cukup baik dan kondisi iklim cukup mendukung (Tabel 6).

Tabel 5. Analisis Biaya Usahatani Padi Sawah di Desa Contoh Provinsi Sulawesi Selatan, 2012

\begin{tabular}{|c|c|c|c|c|}
\hline \multirow{3}{*}{ Uraian } & \multicolumn{2}{|c|}{ Desa Carawali } & \multicolumn{2}{|c|}{ Desa Salujambu } \\
\hline & $\mathrm{MH}$ & $\mathrm{MK}$ & MH & $\mathrm{MK}$ \\
\hline & \multicolumn{4}{|c|}{ 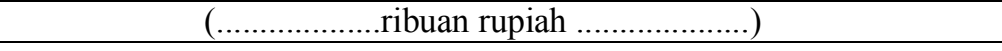 } \\
\hline 1. Biaya saprodi & & & & \\
\hline - Benih & $420(4,94)$ & $409(4,98)$ & $399(4,82)$ & $392(4,72)$ \\
\hline - Pupuk & $865(10,16)$ & $796(9,69)$ & $790(9,54)$ & $722(8,70)$ \\
\hline - Obat-obatan & $410(4,82)$ & $344(4,19)$ & $315(3,81)$ & $350(4,22)$ \\
\hline Jumlah saprodi & $1.695(19,92)$ & $1,549(18,86)$ & $1,504(18,17)$ & $1.464(17,64)$ \\
\hline \multicolumn{5}{|l|}{ 2. Biaya tenaga kerja } \\
\hline - Keluarga & $1.180(13,87)$ & $1.050(12,78)$ & $1.360(16,43)$ & $1.290(15,55)$ \\
\hline - Upahan & $2.100(24,68)$ & $2.280(27,76)$ & $2.040(24,65)$ & $2.200(26,21)$ \\
\hline - Traktor & $780(9,16)$ & $780(9,50)$ & $775(9,36)$ & $775(9,34)$ \\
\hline - Panen*) & $2.575(30,26)$ & $2.375(28,91)$ & $2.440(29,48)$ & $2.410(29,05)$ \\
\hline Jumlah tenaga & $6.635(77,97)$ & $6.485(78,95)$ & $6.615(79,92)$ & $6.675(80,45)$ \\
\hline 3. Biaya lainnya & $180(2,11)$ & $180(2,19)$ & $158(1,91)$ & $158(1,90)$ \\
\hline \multicolumn{5}{|l|}{ 4. Biaya total } \\
\hline - Tanpa keluarga & $7.730(90,83)$ & $7.164(87,22)$ & $6.917(83,69)$ & $7.007(84,45)$ \\
\hline - Dengan keluarga & $8.510(100)$ & $8.214(100)$ & $8.277(100)$ & $8.297(100)$ \\
\hline
\end{tabular}

Sumber : Data Primer, 2012.

Keterangan : ( ) adalah angka persentase kontribusi

*) nilai konversi upah panen natura

Tabel 6. Analisis Gross B/C, Profitabilitas dan Break Even Point (BEP) Usahatani Padi Sawah per Hektar di Desa Contoh Provinsi Sulawesi Selatan, 2012

\begin{tabular}{lrrrr}
\hline \multicolumn{1}{c}{ Uraian } & \multicolumn{2}{c}{ Desa Carawali } & \multicolumn{2}{c}{ Desa Salujambu } \\
\cline { 2 - 5 } & \multicolumn{1}{c}{ MH } & \multicolumn{1}{c}{ MK } & \multicolumn{1}{c}{ MK } \\
\hline 1. Pendapatan kotor usahatani & & & & \\
- Fisik (kg GKP/ha) & 6.200 & 5.700 & 5.900 & 5.600 \\
- Nilai (Rp 000) & 16.120 & 14.820 & 15.340 & 14.600 \\
& & & & \\
2. Biaya total usahatani & & & & \\
- Tanpa keluarga (Rp 000) & 7.730 & 7.164 & 6.917 & 7.007 \\
- Dengan keluarga (Rp 000) & 8.510 & 8.214 & 8.277 & 8.297 \\
3. Keuntungan bersih & & & & \\
- Tanpa keluarga (Rp 000) & & & & \\
- Dengan keluarga (Rp 000) & 8.390 & 7.656 & 8.423 & 7.593 \\
& 7.610 & 6.606 & 7.063 & 6.303 \\
4. Gross B/C & & & & \\
- Tanpa keluarga & & & & \\
- Dengan keluarga & 2,08 & 2,07 & 2,22 & 2,08 \\
& 1,89 & 1,80 & 1,85 & 1,76 \\
5. Profitabilitas (\%) & & & & \\
- Tanpa keluarga (Rp 000) & 52,05 & 51,16 & 54,91 & 52,01 \\
- Dengan keluarga (Rp 000) & 47,21 & 44,57 & 46,04 & 43,17 \\
\hline
\end{tabular}

Sumber : Data Primer, 2012. 


\section{KESIMPULAN DAN SARAN}

Penerapan teknologi budidaya padi sawah oleh petani di lokasi Desa Carawali dan Salujambu, baik pada musim hujan maupun musim kemarau tahun 2012 sudah sesuai dengan paket teknologi anjuran.

Varietas padi yang ditanam petani seluruhnya memakai varietas unggul nasional dan yang paling disukai sistem tanam yang dominan tabela.

Total biaya usahatani padi di lokasi penelitian berkisar antara 8,2 juta $-8,5$ juta rupiah, sedangkan tingkat penerimaan/ pendapatan usahatani sebesar 14,6 - 16,1 juta rupiah dengan tingkat keuntungan bersih sebesar 6,3-7,6 juta rupiah.

Dalam struktur biaya untuk pengadaan sarana produksi, pupuk merupakan komponen dengan porsi terbesar sehingga menjdi faktor kritis dalam adopsi teknologi.

Usahatani padi sawah di lokasi penelitian Kabupaten Sidrap dan Luwu dalam setiap musimnya memberikan nilai Gross B/C $>1$ dan tingkat profitabilitas sebesar 43-47 persen. Dengan demikian usahatani padi tersebut, secara ekonomi menguntungkan dan layak diusahakan.

\section{DAFTAR PUSTAKA}

Adjid, D.A. 1985. Pola Partisipasi Masyarakat Pedesaan dalam Pembangunan Pertanian Berencana : Suatu Survei di Jawa Barat. Disertasi Fakultas Pertanian. Universitas Padjadjaran. Bandung.

Badan Litbang Pertanian. 2005. Prospek dan Arah Pengembangan Agribisnis Padi. Departemen Pertanian. Jakarta.

Departemen Pertanian. 2008. Panduan Pelaksanaan Sekolah Lapang Pengelolaan Tanaman Terpadu (SLPTT) Padi.

Djoeroemana, S., E.I.T. Salaen and W. Nope. 2007. An Overview of Environmental Socio-cultural Economic and Politic Aspect of Rural Development in East Nusa Tenggara. Dalam Proc. Workshop to Identify Sustainable Rural Livelihoods Held in Kupang, Indonesia. 5-7 April 2006. ACIAR, Canberra.
Fagi, A.M. 2004. Penelitian Padi Menuju Revolusi Hijau Lestari. Dalam : Inovasi Pertanian Tanaman Pangan. Pusat Penelitian dan Pengembangan Tanaman Pangan. Bogor.

Farida, S. 2006. Sistem Perilaku Suatu Organisasi. Agro-Humaniora 4(10):9-10.

Gunawan, M. dan E. Pasandaran. 1989. Alokasi Masukan dalam Sistem Sakap. Prosiding Patanas: Evolusi Kelembagaan Pedesaan di Tengah Perkembangan Teknologi Pertanian. Pusat Agro Ekonomi. Bogor.

Hamdani, C. 2006. Birokrat Pertanian Harus Dekat dengan Petani. Agro-Humaniora 4(10):9-10.

Kasryno, F., E. Pasandaran, P. Simatupang, Erwidodo dan T. Sudaryanto. 2001. Membangun Kembali Sektor Pertanian dan Kehutanan. Buku I hlm 1-31. Prosiding Seminar Perspektif Pembangunan Pertanian dan Kehutanan ke Depan. Pusat Penelitian dan Pengembangan Sosial Ekonomi Pertanian. Bogor.

Las, I., N. Widiarto dan B. Suprihatini. 2004. Perkembangan Varietas dalam Perpadian Nasional. Dalam : Inovasi Pertanian Tanaman Pangan. Pusat Penelitian dan Pengembangan Tanaman Pangan. Bogor. Hlm 1-25.

Nurmanaf, A.R., Sugiarto, A. Djulin, Supadi, N.K. Agustin, J.F. Sinuraya dan A.K. Zakaria. 2005. Panel Petani Nasional: Dinamika Sosial Ekonomi Rumah Tangga dan Masyarakat Pedesaan. Pusat Analisis Sosial Ekonomi dan Kebijakan Pertanian. Bogor.

Sayaka, B., K. Kariyasa, Waluyo, T. Nurasa dan Y. Marisa. 2006. Kajian Sistem Perbenihan Komoditas Pangan dan Perkebunan. Pusat Analisis Sosial Ekonomi dan Kebijakan Pertanian. Bogor.

Simatupang, P. 2004. Prima Tani sebagai Langkah Awal Pengembangan Sistem dan Usaha Agribisnis Industrial. Makalah Pelatihan Analisis Finansial dan Ekonomi bagi Pengembangan Sistem dan Usaha Agribisnis. Widaya, 29 Nopember - 9 Desember 2004. 
Sumardi. 2006. Koordinasi Membangun Kerjasama yang Terarah. AgroHumaniora 4(1): 9-10.

Sumarno. 2010. Green Agriculture dan Green Food sebagai Strategi Branding dalam Usaha Pertanian. Forum Agro Ekonomi (FAE 28(2): 81-90. Pusat Sosial Ekonomi dan Kebijakan Pertanian. Bogor.

Sumarno. 2011. Peningkatan Produksi Beras Nasional dan Peran Teknologi. Sinar Tani. Edisi 16-22 Maret 2011. No: 3397. Tahun $X L I$.

Swastika, D.K.S., J. Wargiono, B. Sayaka, A. Agustian dan V. Darwis. 2006. Kinerja dan Prospek Pembangunan Pertanian
Tanaman Pangan di Indonesia. Pusat Analisis Sosial Ekoomi dan Kebijakan Pertanian. Bogor.

Syahyuti. 2006. 30 Konsep Penting dalam Pembangunan Pedesaan dan Pertanian. Penjelasan Konsep, Istilah, Teori dan Indikator srta Variabel. Bina Rena Pariwara. Jakarta

Syahyuti. 2008. Peranan Modal Sosial (Social Capital) dalam Perdagangan Hasil Pertanian. Forum Penelitian Agro Ekonomi (FAE) 26(1), Juli 2008. Pusat Analisis Sosial Ekonomi dan Kebijakan Pertanian. Bogor. 
Lampiran 1. Keragaan Produksi dan Produktivitas Padi Sawah di Tingkat Responden pada Lokasi Desa Carawali, Sulawesi Selatan, 2012

\begin{tabular}{|c|c|c|c|c|c|}
\hline \multirow[b]{2}{*}{ No. } & \multirow[b]{2}{*}{$\begin{array}{l}\text { Luas garap } \\
\text { (ha) }\end{array}$} & \multicolumn{2}{|c|}{ Musim Hujan } & \multicolumn{2}{|c|}{ Musim Kemarau } \\
\hline & & $\begin{array}{l}\text { Produksi } \\
\text { (ku GKP) }\end{array}$ & $\begin{array}{l}\text { Produktivitas } \\
\text { (kg GKP/ha) }\end{array}$ & $\begin{array}{l}\text { Produksi } \\
\text { (ku GKP) }\end{array}$ & $\begin{array}{r}\text { Produktivitas } \\
\text { (kg GKP/ha) }\end{array}$ \\
\hline 1. & 0,45 & 27,0 & 6.000 & 24,5 & 5.444 \\
\hline 2. & 0,45 & 27,0 & 6.000 & 25,0 & 5.555 \\
\hline 3. & 0,45 & 28,0 & 6.222 & 25,0 & 5.555 \\
\hline 4. & 0,45 & 28,0 & 6.222 & 25,5 & 5.666 \\
\hline 5. & 0,45 & 28,0 & 6.222 & 25,5 & 5.666 \\
\hline 6. & 0,45 & 28,2 & 6.266 & 26,0 & 5.777 \\
\hline 7. & 0,45 & 28,2 & 6.266 & 26,0 & 5.777 \\
\hline 8. & 0,45 & 28,5 & 6.333 & 27,0 & 6.000 \\
\hline 9. & 0,50 & 29,0 & 5.800 & 27,0 & 5.400 \\
\hline 10. & 0,50 & 30,0 & 6.000 & 27,5 & 5.500 \\
\hline 11. & 0,50 & 30,0 & 6.000 & 28,0 & 5.600 \\
\hline 12. & 0,50 & 30,0 & 6.000 & 28,0 & 5.600 \\
\hline 13. & 0,50 & 31,0 & 6.200 & 28,0 & 5.600 \\
\hline 14. & 0,50 & 31,0 & 6.200 & 28,5 & 5.700 \\
\hline 15. & 0,50 & 31,0 & 6.200 & 28,5 & 5.700 \\
\hline 16. & 0,50 & 31,5 & 6.300 & 28,5 & 5.700 \\
\hline 17. & 0,50 & 31,5 & 6.300 & 29,0 & 5.800 \\
\hline 18. & 0,50 & 32,0 & 6.400 & 29,5 & 5.900 \\
\hline 19. & 0,50 & 32,0 & 6.400 & 29,5 & 5.900 \\
\hline 20. & 0,50 & 32,0 & 6.400 & 30,0 & 6.000 \\
\hline 21. & 0,70 & 42,0 & 6.000 & 39,0 & 5.571 \\
\hline 22. & 0,70 & 42,0 & 6.000 & 39,5 & 5.643 \\
\hline 23. & 0,70 & 43,0 & 6.143 & 39,5 & 5.643 \\
\hline 24. & 0,70 & 43,0 & 6.143 & 39,5 & 5.643 \\
\hline 25. & 0,70 & 43,5 & 6.214 & 39,7 & 5.671 \\
\hline 26. & 0,70 & 43,5 & 6.214 & 40,0 & 5.714 \\
\hline 27. & 0,70 & 43,5 & 6.214 & 40,0 & 5.714 \\
\hline 28. & 0,70 & 44,0 & 6.286 & 40,3 & 5.757 \\
\hline 29. & 0,70 & 44,5 & 6.357 & 40,5 & 5.786 \\
\hline 30. & 0,70 & 45,0 & 6.428 & 41,0 & 5.857 \\
\hline 31. & 1,00 & 60,0 & 6.000 & 56,0 & 5.600 \\
\hline 32. & 1,00 & 61,0 & 6.000 & 56,5 & 5.650 \\
\hline 33. & 1,00 & 62,0 & 6.200 & 57,0 & 5.700 \\
\hline 34. & 1,00 & 62,0 & 6.200 & 57,0 & 5.700 \\
\hline 35. & 1,00 & 63,0 & 6.300 & 57,5 & 5.750 \\
\hline 36. & 1,00 & 63,0 & 6.300 & 58,0 & 5.800 \\
\hline 37. & 1,50 & 92,0 & 6.133 & 84,5 & 5.633 \\
\hline 38. & 1,50 & 93,0 & 6.200 & 85,5 & 5.700 \\
\hline 39. & 1,50 & 94,0 & 6.267 & 86,5 & 5.766 \\
\hline 40. & 1,70 & 105,0 & & & \\
\hline Jumlah & 28,8 & $1.785,5$ & 24.799 & $1.641,5$ & 22.800 \\
\hline Rataan & 1 & 7.200 & 7.200 & 5.700 & 5.700 \\
\hline
\end{tabular}


Lampiran 2. Keragaan Produksi dan Produktivitas Padi Sawah di Tingkat Responden pada Lokasi Desa Salujambu, Sulawesi Selatan, 2012

\begin{tabular}{|c|c|c|c|c|c|}
\hline \multirow[b]{2}{*}{ No. } & \multirow[b]{2}{*}{$\begin{array}{l}\text { Luas garap } \\
\text { (ha) }\end{array}$} & \multicolumn{2}{|c|}{ Musim Hujan } & \multicolumn{2}{|c|}{ Musim Kemarau } \\
\hline & & $\begin{array}{l}\text { Produksi } \\
\text { (ku GKP) }\end{array}$ & $\begin{array}{l}\text { Produktivitas } \\
\text { (kg GKP/ha) }\end{array}$ & $\begin{array}{l}\text { Produksi } \\
\text { (ku GKP) }\end{array}$ & $\begin{array}{l}\text { Produktivitas } \\
\text { (kg GKP/ha) }\end{array}$ \\
\hline 1. & 0,50 & 27,5 & 5.500 & 26,0 & 5.200 \\
\hline 2. & 0,50 & 28,0 & 5.600 & 27,0 & 5.400 \\
\hline 3. & 0,50 & 28,0 & 5.600 & 27,0 & 5.400 \\
\hline 4. & 0,50 & 28,5 & 5.700 & 27,5 & 5.500 \\
\hline 5. & 0,50 & 28,5 & 5.700 & 27,5 & 5.500 \\
\hline 6. & 0,50 & 29,0 & 5.800 & 27,5 & 5.500 \\
\hline 7. & 0,50 & 29,0 & 5.800 & 27,5 & 5.500 \\
\hline 8. & 0,50 & 29,0 & 5.800 & 28,0 & 5.600 \\
\hline 9. & 0,50 & 29,5 & 5.900 & 28,0 & 5.600 \\
\hline 10. & 0,50 & 29,5 & 5.900 & 28,0 & 5.600 \\
\hline 11. & 0,50 & 29,5 & 5.900 & 28,0 & 5.600 \\
\hline 12. & 0,50 & 30,0 & 6.000 & 28,0 & 5.600 \\
\hline 13. & 0,50 & 30,0 & 6.000 & 28,0 & 5.600 \\
\hline 14. & 0,50 & 30,0 & 6.000 & 29,0 & 5.800 \\
\hline 15. & 0,50 & 31,0 & 6.200 & 29,0 & 5.800 \\
\hline 16. & 0,50 & 31,0 & 6.200 & 29,0 & 5.800 \\
\hline 17. & 0,50 & 31,5 & 6.300 & 29,0 & 5.800 \\
\hline 18. & 0,50 & 31,5 & 6.300 & 30,0 & 6.000 \\
\hline 19. & 1,00 & 57,0 & 5.700 & 53,0 & 5.300 \\
\hline 20. & 1,00 & 57,0 & 5.700 & 53,5 & 5.350 \\
\hline 21. & 1,00 & 57,5 & 5.750 & 54,0 & 5.400 \\
\hline 22. & 1,00 & 58,0 & 5.800 & 55,0 & 5.500 \\
\hline 23. & 1,00 & 58,5 & 5.850 & 55,5 & 5.550 \\
\hline 24. & 1,00 & 58,5 & 5.850 & 55,5 & 5.550 \\
\hline 25. & 1,00 & 59,0 & 5.900 & 55,5 & 5.550 \\
\hline 26. & 1,00 & 59,0 & 5.900 & 56,0 & 5.600 \\
\hline 27. & 1,00 & 59,0 & 5.900 & 56,0 & 5.600 \\
\hline 28. & 1,00 & 59,0 & 5.900 & 56,0 & 5.600 \\
\hline 29. & 1,00 & 59,0 & 5.900 & 56,0 & 5.600 \\
\hline 30. & 1,00 & 59,0 & 5.900 & 57,0 & 5.700 \\
\hline 31. & 1,00 & 60,0 & 6.000 & 57,5 & 5.750 \\
\hline 32. & 1,00 & 60,0 & 6.000 & 57,5 & 5.750 \\
\hline 33. & 1,00 & 61,0 & 6.100 & 58,0 & 5.800 \\
\hline 34 & 1,00 & 61,0 & 6.150 & 59,0 & 5.900 \\
\hline 35. & 1,50 & 87,5 & 5.833 & 82,0 & 5.467 \\
\hline 36. & 1,50 & 88,5 & 5.900 & 85,0 & 5.667 \\
\hline 37. & 1,50 & 89,5 & 5.967 & 85,0 & 5.667 \\
\hline 38. & 2,00 & 118,0 & 5.900 & 110,0 & 5.500 \\
\hline 39. & 2,00 & 120,0 & 6.000 & 114,0 & 5.700 \\
\hline 40. & 2,50 & 146,0 & 5.840 & 140,0 & 5.600 \\
\hline Jumlah & 36,0 & $2.124,5$ & $2.360,6$ & $2.015,0$ & $2.238,9$ \\
\hline Rataan & 1 & 5.900 & 5.900 & 5.600 & 5.600 \\
\hline
\end{tabular}

